\title{
RESENHA CRÍTICA: \\ EDUCAÇÃO INTERCULTURAL E FORMAÇÃO DE PROFESSORES ${ }^{i}$
}

Renan Soares de Araújo ${ }^{\text {ii }}$

\begin{abstract}
Resumo: Neste livro se encontram subsídios para se discutir as diferenças culturais, étnicas, geracionais, de gênero, bem como as diferenças físicas e mentais, no âmbito da prática pedagógica e da formação de educadores. As dificuldades e possibilidades emergentes nas relações de saber e de poder nos processos de formação de educadores são discutidas, em vários artigos, sob a perspectiva crítica, inclusiva e democrática. De modo particular, quatro artigos focalizam experiências de formação de educadores realizadas pelo Núcleo "Mover" (UFSC/CNPq). Tanto as análises teóricas, quanto as de experiências de formação de educadores, propõem a perspectiva intercultural crítica de desconstrução da matriz colonial, em busca de caminhos para a construção da cidadania, fundada no respeito, reciprocidade e convivência democrática entre todas as pessoas e grupos socioculturais.
\end{abstract}

Palavras chaves: Educação Intercultural; decolonialidade; formação de professores.

\section{REVIEW: \\ INTERCULTURAL EDUCATION AND TEACHER TRAINING}

\begin{abstract}
This book presents subsidies to discuss cultural, ethnic, generational, gender differences, as well as the physical and mental differences, in the pedagogical practice and the teacher's training processes. The difficulties and possibilities emerging in the relations of knowledge and power in the processes of teacher's training are discussed in several articles under a critical, inclusive and democratic perspective. In particular, four articles focuses on teacher's training experiences conducted by the "Mover" Centre (UFSC/CNPq). Both the theoretical analysis and the training experiences propose, in a critical intercultural perspective, the deconstruction of the colonial matrix, looking for the construction of citizenship ways, based on respect, reciprocity and democratic coexistence between all people and sociocultural groups.
\end{abstract}

Keywords: Intercultural education; decoloniality; teacher training. 
Para quem se interessa pela temática da interculturalidade na educação e sua intersecção com os movimentos sociais, sobretudo em uma perspectiva complexa, crítica e inclusiva, o livro "Educação intercultural e formação de professores" é uma valiosa obra a ser consultada, tanto por sua abordagem histórica, assim como por sua perspectiva analítica e principalmente pelas experiências formativas relatadas.

Essa obra, de autoria de Reinaldo Matias Fleuri, é resultante de sua atuação enquanto coordenador, em colaboração com variados sujeitos que trabalharam juntamente com ele no contexto do Núcleo de Pesquisa em Educação Intercultural e Movimentos Sociais, mais conhecido como Núcleo MOVER, vinculado a Universidade Federal de Santa Catarina (UFSC), que foi criado no ano de 1994, com a perspectiva de possibilitar a constituição de uma verdadeira articulação e diálogo entre as investigações e o conhecimento produzido no âmbito acadêmico e a realidade de luta dos movimentos sociais populares.

Para o Núcleo MOVER, na realização de uma pesquisa científica não se trata de produzir quaisquer conhecimentos, mas de construir conhecimentos alinhados com a ótica freiriana, compreendendo que o conhecimento para ser construído necessita de um movimento permanente de confronto com a realidade, sendo a realidade a sua verdadeira fonte de conhecimentos (FREIRE, 2015).

Essa proposta de atuação expõe de maneira inequívoca o objetivo de inaugurar processos de reorientação da tradicional e conservadora relação estabelecida entre a universidade e a sociedade - insuflada da concepção que tem a instituição universitária como redentora do saber que deve ser "transmitido" à população. Ao revés, o modus operandi do Núcleo MOVER funciona como forma de superar o paradigma que concebe as pessoas das classes populares como "incultos" ou como "recipientes vazios" a serem "preenchidos". Como assinalado por Reinaldo Fleuri (2019), gradativamente os sujeitos dos movimentos sociais vêm sendo reconhecidos e admitidos como não meros consumidores, mas sim como produtores de conhecimentos críticos - em decorrência da constante problematização e transformação do cenário social, cultural e ambiental em que estão inseridos. Com isso em vista, variadas instituições universitárias, na busca pela compreensão e enfrentamento de problemáticas locais e globais, têm estabelecido relações significativas de diálogo crítico e de parceria com esses atores sociais. Conforme ressalta o mesmo, esse panorama epistemológico 
tem indicado a transição para um nova forma de construção de conhecimento, designado por ele como conversitário.

De acordo com Reinaldo Fleuri (2019), a limitação epistemológica da ciência não provém de seu caráter "científico", mas exatamente da exígua cientificidade decorrente de seu paradigma vigente - marcado por um bloqueio naturalístico a respeito de dimensões que se relacionam ao subjetivo, ao social e ao cultural. Em tal sentido, para que o conhecimento seja considerado suficientemente científico, é necessário que esse consiga elucidar racionalmente os fatos ponderando dimensões de ordem natural, subjetiva, social, cultural e ecológica assim como a sua possível relação conflitante.

Cabe destacar que os textos compilados nesse livro são frutos desse diálogo autêntico entre a universidade e os movimentos sociais populares - no melhor sentido da palavra, pois “o significado de diálogo: 'diá' (através) e 'logos' (conhecimento) significa o conhecimento que se constrói em relação" (FLEURI, 2018, p. 148). Como expõe de maneira incontestável a experiência do Núcleo MOVER, a partir dessa interação dialógica que vem se fundindo entre instituição universitária e movimentos sociais - com ênfase em uma perspectiva dialética, intercultural e política da práxis científica -, manifesta-se uma nova forma de produção de conhecimento crítico e de relação educativa, denominada por Reinaldo Fleuri (2019) de conversidade. Conforme assinala o autor:

[...] Não se trata apenas de construir uma narrativa que consolida sua coesão com base em opções e visões de mundo constituídas em uma única direção (uni-versidade). Não se trata também de meramente reconhecer a diversidade de opções e visões de mundo que constituem a realidade sociocultural do mundo contemporâneo (pluri-versidade). Trata-se de construir e potencializar os múltiplos dispositivos, as diferentes estratégias, os variados processos, as várias linguagens e narrativas capazes de suscitar e sustentar a relação de mútua aprendizagem entre os diferentes sujeitos e entre suas respectivas culturas (con-versidade) (FLEURI, 2019, p. 49, grifo do autor).

Em tal sentido, o livro é composto de oito capítulos, tendo a educação intercultural como elemento transversal. Mas não só isso, o que se observa no conjunto da obra, é o esforço perene em estruturar uma concepção de educação intercultural crítica, inclusiva e 
atualizada no contexto das lutas sociais contra os processos crescentes de exclusão social inerentes à globalização econômica (FLEURI, 2018, p. 21).

Nessa obra, é possível acompanhar o desenvolvimento de um debate teórico profícuo no campo das ciências humanas e sociais, em particular sobre categorias conceituais como “cultura", “identidade”, “diferença", “inclusão", “diversidade”, “monoculturalismo", "multiculturalismo", "pluriculturalismo", "transculturalismo" e "interculturalismo". E, para além disso, Reinaldo Fleuri avança e propõe um "salto lógico", situando a concepção intercultural de educação em relação com a perspectiva epistemológica da "complexidade", tendo como referência as proposições de autores como Gregory Bateson e Edgar Morin. Para ele, a concepção intercultural da educação:

[...] reconhece o valor intrínseco de cada cultura e defende o respeito recíproco entre diferentes grupos identitários. Além disso, [...] propõe construir a relação recíproca entre eles. Uma relação que se dá, não abstratamente, mas entre pessoas concretas. Entre sujeitos que decidem construir contextos e processos de aproximação, de conhecimento recíproco e de interação. Relações estas que produzem mudanças em cada indivíduo, favorecendo a consciência de si e reforçando a própria identidade. Sobretudo, promovem mudanças estruturais nas relações entre grupos. Estereótipos e preconceitos - legitimadores de relações de sujeição ou de exclusão - são questionados e, até mesmo superados, na medida em que sujeitos diferentes se reconhecem a partir de seus contextos, de suas histórias e de suas opções. [...] implica em [...] necessidade de oferecer oportunidades educativas a todos, respeitando e integrando a diversidade de sujeitos e de seus pontos de vista. [Assim como demanda a] [...] necessidade de desenvolver processos educativos, metodologias e instrumentos pedagógicos que deem conta da complexidade das relações humanas entre indivíduos e culturas diferentes (FLEURI, 2018, p. 46).

A relevância dessa obra reside não apenas em sua originalidade, mas sobretudo no fato dela ser fruto de mais de duas décadas de um trabalho intenso e compromissado de Reinaldo Fleuri à frente do Núcleo MOVER em articulação interdisciplinar e interinstitucional com variados grupos universitários e movimentos sociais. Como exemplo disso, pode-se destacar a experiência do Projeto Rizoma, uma iniciativa em rede de cooperação científica e social que durou de 2001 a 2003 e envolveu em sua sustentação o Núcleo MOVER em colaboração com o Núcleo de Pesquisa em Movimentos Sociais (NPMS) da UFSC, o Núcleo de Identidade, 
Gênero e Subjetividade (NIGS) da UFSC e o Núcleo de Estudos, Pesquisa e Extensão sobre Movimentos Sociais (NEPEMOS) da Fundação Universidade Regional de Blumenau (FURB). Articulação que se posicionou em torno de temas como: movimentos sociais, identidade, gênero, educação e associativismo civil. Experiência que rendeu frutos tanto por ocasião da sistematização de produções bibliográficas, bem como em decorrência da organização de um evento de dimensão internacional, que possibilitou o estabelecimento de parcerias e a criação de relações de cooperação com outros grupos, instituições e movimentos sociais.

Em seu livro, Reinaldo Fleuri enfrenta o desafio de olhar a questão da alteridade e da diferença étnica, de gênero, física, mental e geracional a partir de uma percepção “interdisciplinar e complexa, sobre a dimensão híbrida e 'deslizante' do 'inter-' (-cultural, étnico, -geracional, -sexual, -grupal...) constitutiva de possibilidades de transformação e de criação" (FLEURI, 2018, p. 77), dando subsídios importantes para se pensar em possibilidades para trabalhar e superar a questão da diferença no âmbito da educação.

Ademais, Fleuri provoca e alimenta o debate sobre as dificuldades e possibilidades da estruturação de processos de formação de educadores alinhados com um horizonte crítico, inclusivo e democrático, de modo que muito além do conteúdo a ser ensinado, sejam valorizados aspectos relativos as subjetividades e intersubjetividades que se articulam no processo educativo, compreendendo as tensões que se estabelecem entre as relações de saber e poder que se desenvolvem no cenário escolar e na prática educativa. A esse respeito, destacam-se a organização de alguns cursos: Curso de capacitação de formadores para a educação inclusiva, realizado pelo Serviço Social da Indústria do Estado de Santa Catarina em parceria com a Fundação de Amparo à Pesquisa e Extensão Universitária da UFSC; Curso de Educação para Diversidade e Cidadania, realizado a partir da Universidade Aberta do Brasil, Secretaria de Educação Continuada, Alfabetização e Diversidade (SECAD) e pela Rede para a Diversidade do Ministério da Educação e; Curso de formação de educadores populares em capoeira na perspectiva intercultural, em parceria com a Confraria Catarinense de Capoeira experiências detalhadas em sua elaboração e execução em diferentes capítulos do livro.

Não obstante, Reinaldo Fleuri expõe as bases em que se estrutura o racismo e a intolerância religiosa. Mas para além disso, propõe a adoção de uma perspectiva intercultural 
crítica da educação para promoção dos direitos humanos e a desconstrução da matriz colonial, como passo fundamental para a decolonização do poder, do saber, do ser e do viver, na consolidação de caminhos para a construção da cidadania, fundada no respeito, reciprocidade e convivência democrática entre todas as pessoas, independentemente de sua convicção religiosa, compreendendo a diversidade cultural do Brasil.

Finalmente, importa salientar que para o momento em que vivemos na atualidade brasileira, de oposição e contestamento aos direitos humanos (em que se torna comum escutar frases como "direitos humanos para humanos direitos"); de falta de respeito e acusação de doutrinação marxista aos professores, de cerceamento do livre pensar e de ameaças de expurgo as ideias de Paulo Freire (em tempos de "escola sem partido"), essa obra de Reinaldo Fleuri apresenta-se como uma luz no fim do túnel, pois como disse Paulo Freire (2001), se a educação por si só não transforma a sociedade, tampouco sem ela a sociedade muda.

\section{REFERÊNCIAS}

FLEURI, R.M. Conversidade: diálogo entre universidade e movimentos sociais. João Pessoa: Editora do CCTA, 2019.

FLEURI, R.M. Educação intercultural e formação de professores. João Pessoa: Editora do CCTA, 2018.

FREIRE, P. Extensão ou comunicação? 17. ed. São Paulo: Paz e Terra, 2015.

FREIRE, P. Política e educação: ensaios. 5. ed. São Paulo: Cortez, 2001.

\footnotetext{
${ }^{\text {i }}$ Obra: FLEURI, Reinaldo Matias. Educação intercultural e formação de professores. João Pessoa: Editora do Centro de Comunicação, Turismo e Artes da Universidade Federal da Paraíba (CCTA/UFPB), 2018. 303p.

ii Graduado em Nutrição pela Universidade Federal da Paraíba - UFPB. É membro do Grupo de Pesquisa em Extensão Popular - EXTELAR, vinculado a UFPB. Integra a Articulação Nacional de Extensão Popular.
} 